\title{
Increased lysophosphatidylcholine acyltransferase 1 expression is unrelated to prognosis of esophageal cancer patients
}

\author{
Eugen Bellon ${ }^{1} \mathbb{0} \cdot$ Katharina Grupp ${ }^{1} \cdot$ Tarik Ghadban $^{1} \cdot$ Michael Tachezy $^{1} \cdot$ Kai Bachmann $^{1} \cdot$ Jakob Robert Izbicki ${ }^{1}$. \\ Ronald Simon ${ }^{2} \cdot$ Guido Sauter $^{2} \cdot$ Claudia Hube-Magg $^{2} \cdot$ Nathaniel Melling $^{1}$
}

Received: 25 November 2020 / Accepted: 5 June 2021 / Published online: 19 June 2021

(c) The Author(s) 2021

\begin{abstract}
Introduction Lysophosphatidylcholine acyltransferase 1 (LPCAT1) has repeatedly been suggested to be associated with tumorigenesis. To evaluate the role of LPCAT1 in esophageal cancer, LPCAT1 immunostaining was analyzed on a tissue microarray containing samples from esophageal cancer patients.

Results In benign esophageal tissue, LPCAT1 staining was detectable in low intensities. LPCAT1 staining was increased in malignant as compared to benign esophageal tissue and was found in high intensity in $26.4 \%$ of 288 interpretable esophageal adenocarcinomas (EACs) and in $23.2 \%$ of 211 squamous cell carcinomas (ESCCs). Increased LPCAT1 staining was linked to undifferentiated tumor grading in both subtypes of EACs and ESCCs $(p=0.0273$ and $p=0.0085)$.

Conclusion However, LPCAT1 was not associated with prognosis of EAC and ESCC patients $(p=0.6838$ and $p=0.4695)$ and thus cannot be considered a prognostic biomarker in esophageal cancers.
\end{abstract}

Keywords LPCAT1 $\cdot$ Tissue microarray $\cdot$ Esophageal cancer

\section{Introduction}

Esophageal cancer is the eighth most common cancer in the world and one of the most malignant types of cancer (Song et al. 2014). The 5-year survival rate for all patients with esophageal cancer is $10 \%$, which is related to the fact that there are no adequate mechanisms for early detection and treatment (Song et al. 2014). The discovery of new markers that could be used to predict tumor behavior or personalized therapy in individual patients is of great importance.

Certain processes in the cell, such as motility, growth, differentiation, and proliferation, which are ultimately also important for tumor cells, are influenced by changes in

Eugen Bellon and Katharina Grupp contributed equally to the manuscript.

Eugen Bellon

e.bellon@uke.de

1 General, Visceral and Thoracic Surgery Department and Clinic, University Medical Center Hamburg-Eppendorf, Hamburg, Germany

2 Institute of Pathology, University Medical Center Hamburg-Eppendorf, Hamburg, Germany lipid metabolism (Santos und Schulze 2012). In addition, changes in superficial membrane potential and phospholipid composition are associated with malignancy (Dobrzyńska et al. 2005), and alterations of membrane lipid levels can also influence cell proliferation and viability (Preetha et al. 2005). Lysophosphatidylcholine acyltransferase 1 (LPCAT1) plays a key role in the synthesis of various individual phosphatidylcholine samples, which are important components of cell membranes and lipoproteins. (Kent 2005). LPCAT1 plays an important role in important physiological processes in the body such as the production of surfactants in the lungs (dipalmitoylphosphatidylcholine) (Bridges et al. 2010; Chen et al. 2006; Nakanishi et al. 2006), in the non-inflammatory platelet-activation factor remodeling pathway (Harayama et al. 2008) and in the retinal photoreceptor homeostasis (Chen et al. 2006).

Overexpression of LPCAT1 has been found in several malignancies, such as colon cancer. Dueke et al. (1996) showed that the amount of phospholipids in colon cancer tissue is greatly increased and increased synthesis of membrane phospholipids is required for rapid growth during tumor development (Dueke et al. 1996). In addition, analyzes from colon cancer cell lines have shown a significant growth advantage when overexpressing LPCAT1 (Mansilla 
et al. 2009). In esophageal cancer, one transcriptome analysis suggested an upregulation of LPCAT1 (Warnecke-Eberz et al. 2016). To further evaluate the potential of LPCAT1 as a prognostic biomarker in esophageal cancer, we analyzed a tissue microarray (TMA) containing more than 600 esophageal cancer specimens. In summary, our data identify an overexpression of LPCAT1 in a subset of esophageal cancers with undifferentiated tumor grading. However, since LPCAT1 expression was unrelated to prognosis of patients, LPCAT1 expression cannot be considered as a prognostic biomarker in esophageal cancers.

\section{Materials and methods}

\section{Esophageal cancer TMA}

A TMA was constructed from cancer tissues after radical esophagectomies from 359 esophageal adenocarcinoma and 254 esophageal squamous cell carcinoma patients treated at the Department of General, Visceral and Thoracic Surgery at the University Medical Center Hamburg-Eppendorf in a period from 1997 to 2018. The 8th edition of the TNM classification for esophageal cancer was used for staging. Follow-up data were available for 359 EAC and 254 ESCC patients with a median follow-up of 17.3 and 12.2 months (range 0-208 and 0-191 months). A 2-year follow-up was available for $39 \%$ of the patients and a 5-year follow-up for $26 \%$ of the patients. Our results show an overall 5-year survival of $35 \%$ for EACs and $15 \%$ for SCCs, which is in line with survival rates from the literature (Pennathur et al. 2013; Siegel et al. 2012). All esophagus specimens were analyzed according to a standard procedure, including complete embedding of the entire esophagus for histological analysis. The TMA manufacturing process was described earlier in detail (Mirlacher und Simon 2010). In short, one $0.6 \mathrm{~mm}$ core was taken from a representative tissue block from each patient. The tissues were distributed among 2 TMA blocks. For internal controls, each TMA block also contained various control tissues, including normal esophageal tissue. The study was approved by the Ethics commission Hamburg, and conducted in accordance with the Declaration of Helsinki. Usage of routinely archived formalin fixed leftover patient tissue samples for research purposes by the attending physician is approved by local laws and does not require written consent (HmbKHG, §12,1).

\section{Immunohistochemistry}

Freshly cut TMA sections were immunostained in 1 day and in one experiment. Slides were deparaffinized and exposed to heat-induced antigen retrieval for $5 \mathrm{~min}$ in an autoclave at $121{ }^{\circ} \mathrm{C}$ in $\mathrm{pH} 7.8$ Tris-EDTA-Citrate buffer. Primary antibody specific for LPCAT1 (rabbit, ProteinTech; at $1 / 1350$ dilution) was applied according to the manufacturer's directions. Bound antibody was then visualized using the EnVision Kit (Dako, Glostrup, Denmark). LPACT1 staining was homogenous in the analyzed tumor samples and staining intensity was thus semiquantitatively assessed in the following two categories: low and high immunostaining. Number of stained cells were counted in each tissue core $(0.6 \mathrm{~mm}$ diameter), representing approximately one $40 \times$ high power field (HPF). Intensity was grouped in relation to the count distribution quantities according to the median into "low" ( $n<$ median) and "high" ( $n \geq$ median). The method of classification was previously described (Hanke et al. 2015; Melling et al. 2019).

\section{Statistical analysis}

Statistical calculations were performed with JPM 9 software (SAS Institute Inc., NC, USA). Contingency tables and the chi-squared test were performed to search for associations between molecular parameters and tumor phenotype. Survival curves were calculated according to Kaplan-Meier. The Log-Rank test was applied to detect significant survival differences between groups. Cox proportional hazards regression analysis was performed to test the statistical independence and significance between pathological, molecular, and clinical variables. Logistic regression was used to quantify the area under receiver-operator curve (ROC).

\section{Results}

\section{Technical aspects}

A total of 288 of 359 (80.2\%) EACs and 211 of 254 (83.1\%) ESCCs were interpretable for IHC analysis. Reasons for noninformative tissue cores included a lack of tissue or absence of unequivocal cancer cells on individual TMA spots.

\section{IHC of LPCAT1}

LPCAT1 expression was generally cytoplasmic and occasionally showed a granular pattern. Intensity of LPCAT1 expression was increased in malignant as compared to benign esophageal tissue. Twenty benign tissues were analyzed. These specimens were retrieved from non-malignant esophagectomy specimens and served as control tissues for IHC staining, together with various other control tissues. None of the benign specimens showed high-intensity staining. 

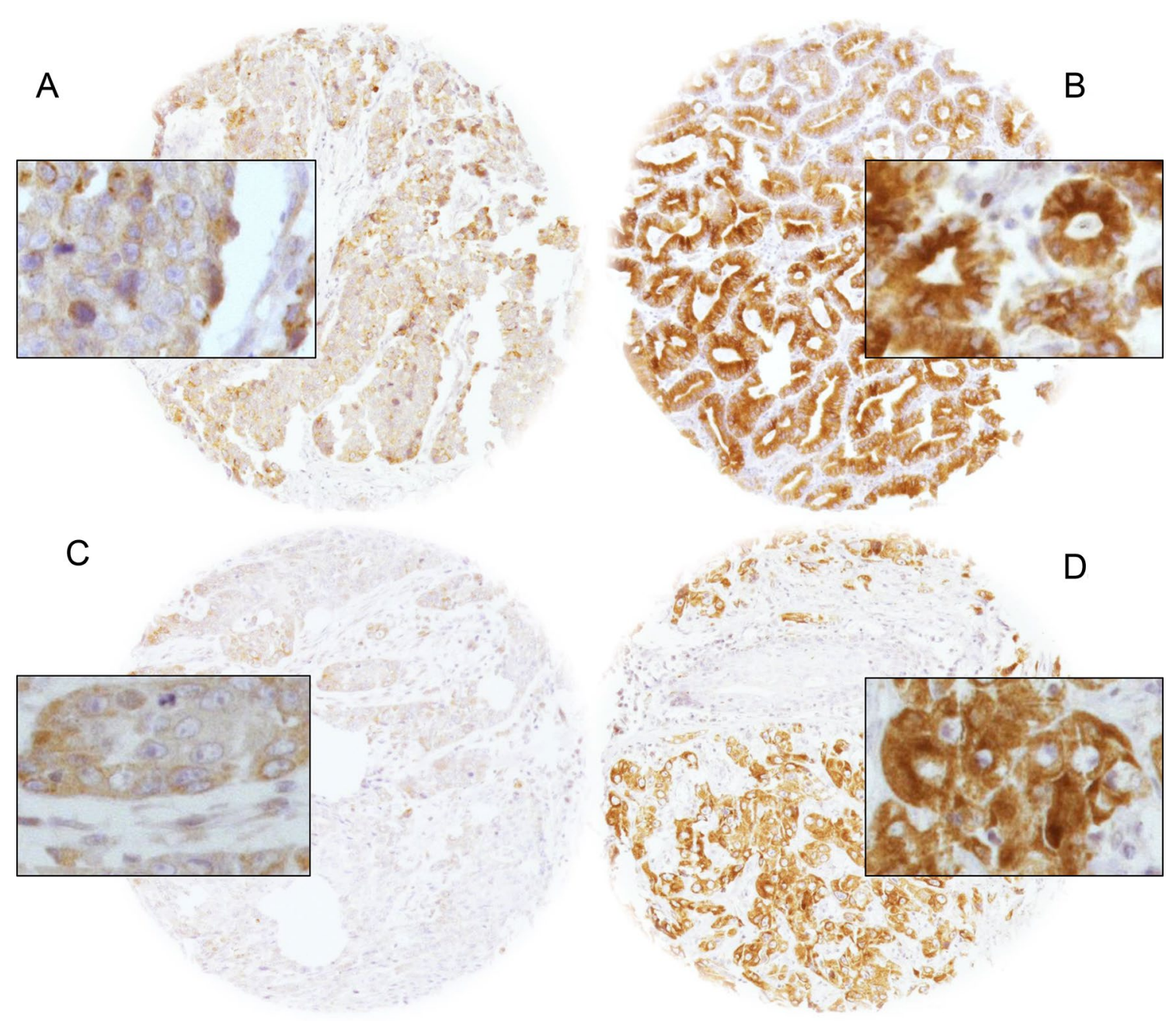

Fig. 1 Immunohistochemical images of LPCAT1 staining. Images of low and high LPCAT1 expression in EACs (A and B) and ESCCs (C and D)

Representative images of LPCAT1 immunostaining are shown in Fig. 1.

\section{Association of LPCAT1 expression with tumor phenotype and prognosis of patients}

Increased LPCAT1 expression was linked to undifferentiated tumor grading in both subtypes of EACs and ESCCs $(p=0.0273$ and $p=0.0085$ ). The clinico-pathological parameters relative to LPCAT1 expression are shown in Tables 1 and 2. LPCAT1 staining was not associated with prognosis of EAC and ESCC patients $(p=0.6838$ and $p=0.4695$; Fig. 2).

\section{Discussion}

The results of our study do not support LPCAT1 immunostaining as a prognostic marker in esophageal cancer.

In the present immunohistochemical study, LPCAT1 immunostaining was increased in malignant as compared to benign esophageal tissue. High LPCAT1 immunostaining was detectable in $26.4 \%$ and $23.2 \%$ of the interpretable EACs and ESCCs. These results are generally in line with one earlier transcriptome analysis, which suggested an upregulation of LPCAT1 in both histological subtypes of esophageal cancers (Warnecke-Eberz et al. 2016).

The fact, that LPCAT1 expression was enhanced in malignant as compared to benign esophageal cancer may suggest a relevant role of LPCAT1 during esophageal tumorigenesis. This assumption matches several earlier studies implicating tumor relevant functional consequences of alterations in the lipid metabolism (Furuta et al. 2010; Santos und Schulze 
Table 1 Clinico-pathological parameters relative to LPCAT1 IHC results in EACs

\begin{tabular}{|c|c|c|c|c|}
\hline \multirow[t]{2}{*}{ Parameter } & \multicolumn{4}{|c|}{ Immunostaining } \\
\hline & Evaluable $(n)$ & Low $(\%)$ & High $(\%)$ & $p$ value \\
\hline Tumors & 288 & 73.61 & 26.39 & \\
\hline Age group & & & & 0.598 \\
\hline$<65$ years & 98 & 75.51 & 24.49 & \\
\hline$>65$ years & 190 & 72.63 & 27.37 & \\
\hline Sex & & & & 0.3824 \\
\hline Male & 244 & 74.59 & 25.41 & \\
\hline Female & 44 & 68.18 & 31.82 & \\
\hline Tumor stage & & & & 0.0241 \\
\hline pT1 & 59 & 57.63 & 42.37 & \\
\hline pT2 & 34 & 76.47 & 23.53 & \\
\hline pT3 & 173 & 78.03 & 21.97 & \\
\hline pT4 & 20 & 80 & 20 & \\
\hline UICC stage & & & & 0.0043 \\
\hline I & 58 & 55.17 & 44.83 & \\
\hline II & 38 & 84.21 & 15.79 & \\
\hline III & 164 & 76.83 & 23.17 & \\
\hline IV & 26 & 80.77 & 19.23 & \\
\hline Grading & & & & 0.0273 \\
\hline G1 & 14 & 57.14 & 42.86 & \\
\hline $\mathrm{G} 2$ & 107 & 72.9 & 27.1 & \\
\hline G3 & 158 & 77.22 & 22.78 & \\
\hline G4 & 5 & 20 & 80 & \\
\hline R status & & & & 0.3235 \\
\hline R0 & 209 & 72.25 & 27.75 & \\
\hline $\mathrm{R} 1$ & 71 & 76.06 & 23.94 & \\
\hline $\mathrm{R} 2$ & 3 & 100 & 0 & \\
\hline $\mathrm{pN}$ category & & & & 0.1229 \\
\hline N0 & 88 & 27.14 & 41.33 & \\
\hline N1 & 50 & 19.05 & 13.33 & \\
\hline N2 & 64 & 24.29 & 17.33 & \\
\hline N3 & 83 & 29.52 & 28 & \\
\hline M status & & & & 0.3708 \\
\hline M0 & 262 & 72.9 & 27.1 & \\
\hline M1 & 26 & 80.77 & 19.23 & \\
\hline
\end{tabular}

2012; Menendez 2010; Menendez und Lupu 2007; Suburu und Chen 2012). Thus, activation of lipid biosynthesis and lipid remodeling has been suggested as a common feature of cancer cells and overexpression of several proteins involved in lipid metabolism, such as fatty acid-binding protein (Morgan et al. 2008), fatty acid synthase (Flavin et al. 2010a, b; SHAH et al. 2006), Caveolin-1 (Freeman et al. 2012) or fatty acid elongase 7 (Tamura et al. 2009) have been associated with tumorigenesis. Since LPCAT1 overexpression is also observed in aggressive forms of a broad variety of other cancer types (Uehara et al. 2016; Shida-Sakazume et al. 2015; Diefenbach et al. 2006) a general role of this protein during
Table 2 Clinico-pathological parameters relative to LPCAT1 IHC results in ESCCs

\begin{tabular}{|c|c|c|c|c|}
\hline \multirow[t]{2}{*}{ Parameter } & \multicolumn{4}{|c|}{ Immunostaining } \\
\hline & Evaluable $(n)$ & Low (\%) & High (\%) & $p$ value \\
\hline Tumors & 211 & 76.78 & 23.22 & \\
\hline Age group & & & & 0.5792 \\
\hline$<65$ years & 76 & 75 & 25 & \\
\hline$>65$ years & 134 & 78.36 & 21.64 & \\
\hline Sex & & & & 0.9408 \\
\hline Male & 154 & 77.27 & 22.73 & \\
\hline Female & 56 & 76.79 & 23.21 & \\
\hline Tumor stage & & & & 0.3838 \\
\hline pT1 & 36 & 86.11 & 13.89 & \\
\hline pT2 & 39 & 79.49 & 20.51 & \\
\hline pT3 & 123 & 73.98 & 26.02 & \\
\hline pT4 & 13 & 69.23 & 30.77 & \\
\hline UICC stage & & & & 0.6182 \\
\hline I & 48 & 83.33 & 16.67 & \\
\hline II & 54 & 75.93 & 24.07 & \\
\hline III & 99 & 75.76 & 24.24 & \\
\hline IV & 9 & 66.67 & 33.33 & \\
\hline Grading & & & & 0.0085 \\
\hline G1 & 3 & 100 & 0 & \\
\hline G2 & 131 & 83.21 & 16.79 & \\
\hline G3 & 76 & 65.79 & 34.21 & \\
\hline G4 & 0 & 0 & 0 & \\
\hline $\mathrm{R}$ status & & & & 0.1189 \\
\hline R0 & 154 & 79.87 & 20.13 & \\
\hline $\mathrm{R} 1$ & 47 & 65.96 & 34.04 & \\
\hline $\mathrm{R} 2$ & 8 & 87.5 & 12.5 & \\
\hline pN category & & & & 0.8271 \\
\hline No & 90 & 75.56 & 24.44 & \\
\hline N1 & 51 & 74.51 & 25.49 & \\
\hline $\mathrm{N} 2$ & 41 & 80.49 & 19.51 & \\
\hline $\mathrm{N} 3$ & 27 & 81.48 & 18.52 & \\
\hline M status & & & & 0.3416 \\
\hline M0 & 202 & 77.72 & 22.28 & \\
\hline M1 & 8 & 62.5 & 37.5 & \\
\hline
\end{tabular}

tumor progression has been suggested. Based on its molecular function as a key enzyme of lipid synthesis in the Land's cycle, it is believed that LPCAT1 upregulation reflects the increased demand for lipid-depending cellular structures such as membranes and fatty acids in rapidly proliferating tumor cells (Currie et al. 2013). This is also supported by a study demonstrating that inhibition of enzymes of the Land's cycle limits the growth of cancer cells and reduces tumorigenesis in various tumor cell models (Flavin et al. 2010a, b).

The results of our study identify LPCAT1 as a further protein of the lipid metabolism, which is involved in esophageal carcinogenesis. 
A

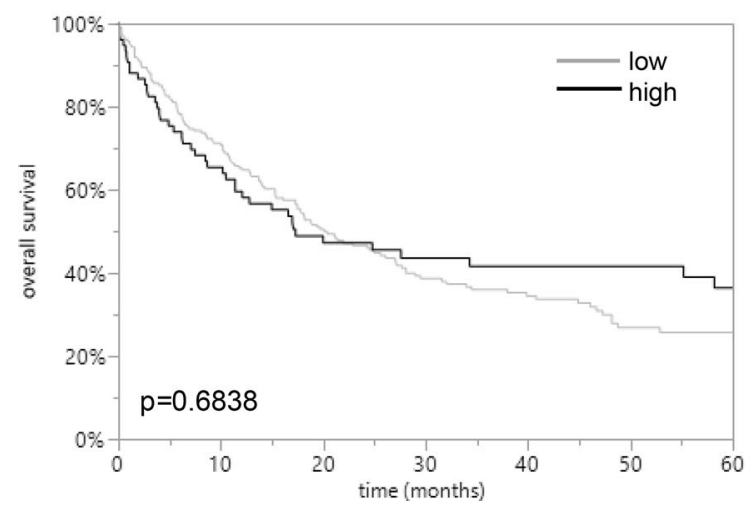

B

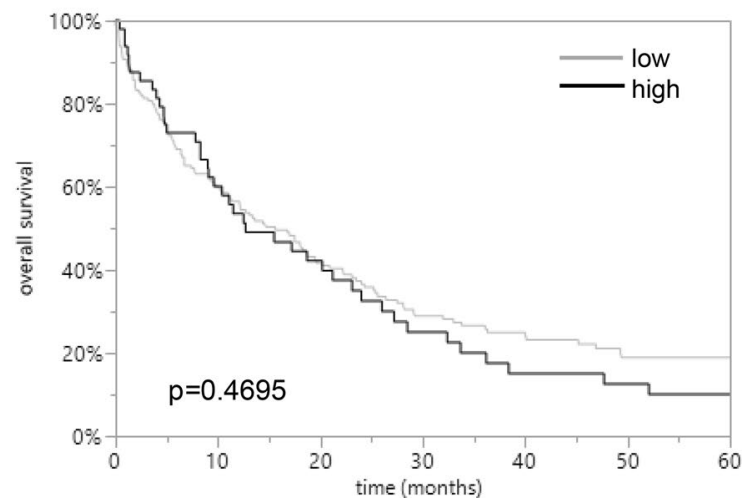

Fig. 2 Prognostic impact of LPCAT1 expression in esophageal cancers. Relationship of LPCAT1 immunostaining intensity with overall survival in $\operatorname{EACs}(p=0.6838 ; \mathbf{A})$ and $\operatorname{ESCCs}(p=0.4695 ; \mathbf{B})$.

It was another aim of this study to analyze the association of LPCAT1 expression with tumor phenotype and prognosis of patients. Increased LPCAT1 expression was significantly linked to undifferentiated tumor grading in both subtypes of EACs and ESCCs. These observations again, suggest a relevant role of LPCAT1 in esophageal tumorigenesis. However, although there was a trend of increased LPCAT1 immunostaining in unfavorable esophageal tumor phenotype, LPCAT1 expression was not prognostically relevant. Thus, our study does not support LPCAT1 expression as a potential relevant biomarker in esophageal cancers.

In summary, our data identify an overexpression of LPCAT1 in a subset of esophageal cancers with undifferentiated tumor grading. However, since LPCAT1 expression was unrelated to prognosis of patients, LPCAT1 cannot be considered as a prognostic biomarker in esophageal cancers.

Funding Open Access funding enabled and organized by Projekt DEAL.

\section{Declarations}

\section{Conflict of interest None.}

Open Access This article is licensed under a Creative Commons Attribution 4.0 International License, which permits use, sharing, adaptation, distribution and reproduction in any medium or format, as long as you give appropriate credit to the original author(s) and the source, provide a link to the Creative Commons licence, and indicate if changes were made. The images or other third party material in this article are included in the article's Creative Commons licence, unless indicated otherwise in a credit line to the material. If material is not included in the article's Creative Commons licence and your intended use is not permitted by statutory regulation or exceeds the permitted use, you will need to obtain permission directly from the copyright holder. To view a copy of this licence, visit http://creativecommons.org/licenses/by/4.0/.

\section{References}

Bridges JP, Ikegami M, Brilli LL, Chen X, Mason RJ, Shannon JM (2010) LPCAT1 regulates surfactant phospholipid synthesis and is required for transitioning to air breathing in mice. J Clin Investig 120(5):1736-1748. https://doi.org/10.1172/JCI38061

Chen X, Hyatt BA, Mucenski ML, Mason RJ, Shannon JM (2006) Identification and characterization of a lysophosphatidylcholine acyltransferase in alveolar type II cells. Proc Natl Acad Sci USA 103(31):11724-11729. https://doi.org/10.1073/pnas.0604946103

Currie E, Schulze A, Zechner R, Walther TC, Farese RV Jr (2013) Cellular fatty acid metabolism and cancer. Cell Metab 18:153-161. https://doi.org/10.1016/j.cmet.2013.05.017 (PMID: 23791484)

Diefenbach CS, Soslow RA, Iasonos A, Linkov I, Hedvat C, Bonham L, Singer J, Barakat RR, Aghajanian C, Dupont J (2006) Lysophosphatidic acid acyltransferase- $\beta$ (LPAAT- $\beta$ ) is highly expressed in advanced ovarian cancer and is associated with aggressive histology and poor survival. Cancer 107:1511-1519. https://doi.org/10.1002/cncr.22184

Dobrzyńska I, Szachowicz-Petelska B, Sulkowski S et al (2005) Changes in electric charge and phospholipids composition in human colorectal cancer cells. Mol Cell Biochem 276:113-119. https://doi.org/10.1007/s11010-005-3557-3

Dueck DA, Chan M, Tran K, Wong JT, Jay FT, Littman C, Stimpson R, Choy PC (1996) The modulation of choline phosphoglyceride metabolism in human colon cancer. Mol Cell Biochem 162(2):97-103. https://doi.org/10.1007/BF00227535 (PMID: 8905631)

Flavin R, Peluso S, Nguyen PL, Loda M (2010a) Fatty acid synthase as a potential therapeutic target in cancer. Future Oncol 6(4):551-562. https://doi.org/10.2217/fon.10.11

Flavin R, Peluso S, Nguyen PL, Loda M (2010b) Fatty acid synthase as a potential therapeutic target in cancer. Future Oncol 6:551562. https://doi.org/10.2217/fon.10.11 (PMID: 20373869)

Freeman MR, Yang W, Di Vizio D (2012) Caveolin-1 and prostate cancer progression. In: Jean-François J, Frank PG, Lisanti MP (eds) Caveolins and caveolae. Springer, pp 95-110

Eiji F, Hiroshi O, Aya K, Kounosuke W (2010) Metabolic genes in cancer. Their roles in tumor progression and clinical implications. BBA Rev Cancer 1805:141-152

Hanke T, Melling N, Simon R, Sauter G, Bokemeyer C, Lebok P, Terracciano LM, Izbicki JR, Marx AH (2015) High intratumoral FOXP3 + T regulatory cell (Tregs) density is an independent 
good prognosticator in nodal negative colorectal cancer. Int $\mathbf{J}$ Clin Exp Pathol 8(7):8227-8235

Harayama T, Shindou H, Ogasawara R, Suwabe A, Shimizu T (2008) Identification of a novel noninflammatory biosynthetic pathway of platelet-activating factor. J Biol Chem 283(17):11097-11106. https://doi.org/10.1074/jbc.M708909200

Kent C (2005) Regulatory enzymes of phosphatidylcholine biosynthesis: a personal perspective. Biochem Biophys Acta 1733(1):53-66. https://doi.org/10.1016/j.bbalip.2004.12.008

Mansilla F, da Costa K-A, Wang S, Kruhoffer M, Lewin TM, Orntoft TF et al (2009) Lysophosphatidylcholine acyltransferase 1 (LPCAT1) overexpression in human colorectal cancer. J Mol Med (berl) 87(1):85-97. https://doi.org/10.1007/s00109-008-0409-0

Melling N, Norrenbrock S, Kluth M, Simon R, Hube-Magg C, Steurer S, Hinsch A, Burandt E, Jacobsen F, Wilczak W, Quaas A, Bockhorn M, Grupp K, Tachezy M, Izbicki J, Sauter G, Gebauer F (2019) p53 overexpression is a prognosticator of poor outcome in esophageal cancer. Oncol Lett 17(4):38263834. https://doi.org/10.3892/ol.2019.10020

Menendez JA (2010) Fine-tuning the lipogenic/lipolytic balance to optimize the metabolic requirements of cancer cell growth. Molecular mechanisms and therapeutic perspectives. BBA Mol Cell Biol Lipids 1801(3):381-391. https://doi.org/10.1016/j. bbalip.2009.09.005

Menendez JA, Lupu R (2007) Fatty acid synthase and the lipogenic phenotype in cancer pathogenesis. Nat Rev Cancer 7(10):763777. https://doi.org/10.1038/nrc2222

Mirlacher M, Simon R (2010) Recipient block TMA technique. In: Simon R (ed) Methods in molecular biology. Humana, pp 37-44

Morgan EA, Forootan SS, Adamson J, Foster CS, Fujii H, Igarashi M et al (2008) Expression of cutaneous fatty acid-binding protein (C-FABP) in prostate cancer: potential prognostic marker and target for tumourigenicity-suppression. Int J Oncol 32(4):767-775

Nakanishi H, Shindou H, Hishikawa D, Harayama T, Ogasawara R, Suwabe A, Taguchi R, Shimizu T (2006) Cloning and characterization of mouse lung-type acyl-CoA: lysophosphatidylcholine acyltransferase 1 (LPCAT1): expression in alveolar type II cells and possible involvement in surfactant production. J Biol Chem 281(29):20140-20147. https://doi.org/10.1074/jbc.M600225200

Pennathur A, Gibson MK, Jobe BA, Luketich JD (2013) Oesophageal carcinoma. Lancet 381:400-412

Preetha A, Banerjee R, Huilgol N (2005) Surface activity, lipid profiles and their implications in cervical cancer. J Can Res Ther $1: 180-186$
Santos CR, Schulze A (2012) Lipid metabolism in cancer. FEBS J 279(15):2610-2623. https://doi.org/10.1111/j.1742-4658.2012. 08644.X

Shah U, Dhir R, Gollin S, Chandran U, Lewis D, Acquafondata M, Pflug B (2006) Fatty acid synthase gene overexpression and copy number gain in prostate adenocarcinoma $\{$. Hum Pathol 37(4):401-409. https://doi.org/10.1016/j.humpath.2005.11.022

Shida-Sakazume T, Endo-Sakamoto Y, Unozawa M, Fukumoto C, Shimada K, Kasamatsu A et al (2015) Lysophosphatidylcholine acyltransferase 1 overexpression promotes oral squamous cell carcinoma progression via enhanced biosynthesis of plateletactivating factor. PLoS ONE 10(3):e0120143. https://doi.org/10. 1371/journal.pone. 0120143

Siegel R, Naishadham D, Jemal A (2012) Cancer statistics, 2012. CA Cancer J Clin 62:10-29

Song Y, Li L, Ou Y, Gao Z, Li E, Li X et al (2014) Identification of genomic alterations in oesophageal squamous cell cancer. Nature 509(7498):91-95. https://doi.org/10.1038/nature13176

Suburu J, Chen YQ (2012) Lipids and prostate cancer. Prostaglandins Other Lipid Mediat 98(1-2):1-10. https://doi.org/10.1016/j.prost aglandins.2012.03.003

Tamura K, Makino A, Hullin-Matsuda F, Kobayashi T, Furihata M, Chung S et al (2009) Novel lipogenic enzyme ELOVL7 is involved in prostate cancer growth through saturated long-chain fatty acid metabolism. Can Res 69(20):8133-8140. https://doi. org/10.1158/0008-5472.CAN-09-0775

Uehara T, Kikuchi H, Miyazaki S et al (2016) Overexpression of lysophosphatidylcholine acyltransferase 1 and concomitant lipid alterations in gastric cancer. Ann Surg Oncol 23:206-213. https:// doi.org/10.1245/s10434-015-4459-6

Warnecke-Eberz U, Metzger R, Holscher AH, Drebber U, Bollschweiler E (2016) Diagnostic marker signature for esophageal cancer from transcriptome analysis. Tumour Biol 37(5):6349-6358. https://doi.org/10.1007/s13277-015-4400-4

Publisher's Note Springer Nature remains neutral with regard to jurisdictional claims in published maps and institutional affiliations. 